\title{
Probiotic Bacilli Inhibit Salmonella Biofilm Formation Without Killing Planktonic Cells
}

\begin{abstract}
Mahtab Hassanpour Tazehabadi', Ammar Algburi',3, Igor V. Popov', Alexey M. Ermakov ${ }^{4}$, Vladimir A. Chistyakov ${ }^{4}$, Evgeniya V. Prazdnova ${ }^{5}$, Richard Weeks $^{6}$ and Michael L. Chikindas $4,6,7 *$
\end{abstract}

\begin{abstract}
1 Department of Biological Sciences, School of Environmental and Biological Sciences, Rutgers State University, New Brunswick, NJ, United States, ${ }^{2}$ Department of Biotechnology, College of Science, University of Diyala, Baqubah, Iraq, ${ }^{3}$ Department of Scholarship and Cultural Relation, Presidency of Diyala University, Baqubah, Iraq, ${ }^{4}$ Research Laboratory "Agrobiotechnology Center», Don State Technical University, Rostov-on-Don, Russia, ${ }^{5}$ Experimental Mutagenesis Laboratory, Southern Federal University, Rostov-on-Don, Russia, ${ }^{6}$ Health Promoting Naturals Laboratory, School of Environmental and Biological Sciences, Rutgers State University, New Brunswick, NJ, United States, ${ }^{7}$. M. Sechenov First Moscow State Medical University, Moscow, Russia
\end{abstract}

Salmonellosis is a foodborne infection caused by Salmonella. Domestic poultry species

OPEN ACCESS

Edited by: Arun K. Bhunia,

Purdue University, United States

Reviewed by:

Guillermo Tellez,

University of Arkansas, United States

Kristin M. Burkholder, University of New England,

United States

*Correspondence:

Michael L. Chikindas tchikind@sebs.rutgers.edu; micromike123@yahoo.com

Specialty section:

This article was submitted to Food Microbiology,

a section of the journal

Frontiers in Microbiology

Received: 12 October 2020 Accepted: 26 January 2021

Published: 17 February 2021

Citation:

Tazehabadi MH, Algburi A Popov IV, Ermakov AM, Chistyakov VA, Prazdnova EV, Weeks $R$ and Chikindas ML (2021) Probiotic Bacilli Inhibit Salmonella Biofilm Formation Without Killing

Planktonic Cells.

Front. Microbiol. 12:615328. doi: 10.3389/fmicb.2021.615328 are one of the main reservoirs of Salmonella, which causes the foodborne infection salmonellosis, and are responsible for many cases of animal-to-human transmission. Keeping backyard chickens is now a growing trend, increasing the frequency of direct contact with the flock and, by consequence, the incidence of Salmonella infections. Bacillus subtilis KATMIRA1933 and Bacillus amyloliquefaciens B-1895 are probiotic bacilli that produce the bacteriocins subtilosin $A$ and subtilin, respectively. The antimicrobial activity of the two strains was determined against the reference strain Micrococcus luteus ATCC 10420. The cell-free supernatant of $B$. subtilis KATMIRA1933 inhibited biofilm formation by Salmonella enterica subsp. enterica serovar Hadar, Salmonella enterica subsp. enterica serovar Enteritidis phage type 4, and Salmonella enterica subsp. enterica serovar Thompson by $51.1,48.3$, and $56.9 \%$, respectively. The cell-free supernatant of $B$. amyloliquefaciens B-1895 inhibited the biofilm formation of these Salmonella strains by $30.4,28.6$, and $35.5 \%$, respectively. These findings suggest that the bacillus strains may have the potential to be used as probiotics and antibiotic alternatives for the control of Salmonella in poultry. The number of planktonic cells was unaffected by treatment with the cell-free supernatant. A co-culture of the Salmonella strains with either bacilli showed no signs of growth inhibition, suggesting that it might have been quorum sensing that is affected by the two Bacillus strains.

Keywords: probiotics, biofilm inhibition, Salmonella, poultry, Bacillus

\section{INTRODUCTION}

Salmonellae are pathogens in both humans and animals and are responsible for causing salmonellosis, which is most commonly (85\%) a foodborne illness. However, infection due to animal contact and person-to-person transmission of the disease are also possible (Hung et al., 2017). There are approximately 1.2 million cases of non-typhoidal salmonellosis (NTS) in 
the United States each year (Dekker and Frank, 2015; Ajmera and Shabbir, 2020). Pathogenic salmonellae most often act on the gastrointestinal tract, where they are able to colonize and invade the mucosa of the small intestines and colon. The severity of the disease's manifestation depends on the patients' level of sensitivity to the pathogen and how virulent the particular serovar is ${ }^{1}$. NTS typically presents as gastroenteritis with diarrhea, fever, and abdominal cramps, and is generally mild, resolving without treatment within 1-4 days. However, in rare cases, Salmonella infection can progress to an invasive, extra-intestinal disease leading to bacteremia and focal systemic infections known as invasive NTS ${ }^{2}$ (Gal-Mor et al., 2014).

Upon ingestion, the stomach's low $\mathrm{pH}(<3.5)$ is lethal to Salmonella and has a significant impact on the ability of an infectious dose to reach the intestines. Salmonellae also have varying degrees of constitutive and inducible acid resistance, providing some protection, while association with the ingested food matrix may further protect cells (Bertelloni et al., 2017). Additional host defenses include gastrointestinal proteases, defensins, and other innate and adaptive components of the immune system. The intestinal microflora also plays an important role in fighting against salmonellosis by producing antimicrobial substances such as short-chain fatty acids, bacteriocins, and bacteriocin-like inhibitory substances (BLIS) that are thought to be toxic to Salmonella. It is important to note that treatment with antibiotics may change the composition of the intestinal flora and make the host more susceptible to Salmonella infection (Foley et al., 2013).

Salmonella is a Gram-negative, facultative anaerobic, and flagellated bacterial genus containing two species, S. enterica and S. bongori, with more than 2,500 identified serovars. S. enterica subsp. enterica represents the majority of pathogenic salmonellae in humans and other warm-blooded species, accounting for 99.5\% of all isolates (Dekker and Frank, 2015; Wang et al., 2019a). The most common hosts for animal-human transmission are livestock while the main sources of pathogenic Salmonella infecting humans are food products including eggs, egg products, and poultry meat (Chlebicz and Śliżewska, 2018; Akil and Ahmad, 2019). Contaminated foods are the main mode of transmission as Salmonella remains viable and can proliferate on meat and animal products that are not cooked or stored properly. In some cases, humans and animals may become chronic carriers of Salmonella, which can persist for years without obvious clinical signs of infection. The wide array of animal reservoirs, ease of transmission, and the prevalence asymptomatic carriers make salmonellosis an ongoing and critical public health issue. Additionally, the overuse of antibiotics in animals and humans has led to an increase in antibiotic resistant Salmonella. Antibiotic resistance reduces the effectiveness of current treatment strategies, and can extend the carriage time, causing patient to shed the bacteria in their feces over a longer timeframe ${ }^{1}$, increasing the spread and persistance of the illness.

\footnotetext{
${ }^{1}$ https://www.cdc.gov/nationalsurveillance/pdfs/NationalSalmSurveillOverview_ 508.pdf

${ }^{2}$ https://www.merckmanuals.com/professional/infectious-diseases/gramnegative-bacilli/non-typhoidal-salmonella-infections
}

The increased popularity of sustainably and locally produced food is now a major contributing factor to the spread of Salmonella. There is also a growing trend of keeping backyard chickens, often treating them as pets, greatly increasing the incidence of direct human contact with potential Salmonella carriers. Unfortunately, many are unaware of the regulatory guidelines that should be followed when raising chickens. This can result in poor hygiene when handling chickens and eggs, and may also lead to the improper use of antibiotics for the prevention and treatment of infectious diseases (McDonagh et al., 2019). The Centers for Disease Control and Prevention (CDC) has investigated several multistate outbreaks of Salmonella that were found to be linked to direct contact with backyard poultry ${ }^{1}$.

This evidence suggests that contact with poultry, no matter how clean or healthy they appear to be, can make humans sick, especially for children younger than five $e^{1}$. Salmonellosis is rare in poultry older than 2 months, and Salmonella infections are predominantly asymptomatic, furthering the pathogens spread. The $42^{\circ} \mathrm{C}$ body temperature of chicken is believed to reduce the expression of the Salmonella pathogenicity island 1 (SPI-1). However, colonization is still possible with only a small number of cells expressing SPI-1, and the proliferation of Salmonella within the intestines is still possible. Lowered expression of SPI1 is likely one of the factors responsible for the asymptomatic persistence of Salmonella in the chicken GIT (Eade et al., 2019). Since the host chicken is asymptomatic, owners may assume that it is safe to be in close contact with the animal. As a result, the chances of transmission of salmonellosis from an infected chicken to humans are considerably increased (Nair et al., 2018).

Biofilm production is an important virulence factor in Salmonella that contributes to the persistence of Salmonella in the gut of humans and livestock following the initial infection (Fàbrega and Vila, 2013). Biofilms increase the chances of the microorganisms' survival by inducing antimicrobial resistance, mechanical persistence, and the production of virulence factors (Giaouris et al., 2015). For a biofilm to successfully form and remain viable an effective cell-to-cell signaling system must be present. In bacteria, a range of specific and diffusible signaling molecules called autoinducers are produced in response to changes in cell density. Cells within a biofilm can detect and respond to these molecules and are therefore able to coordinate their activities. Salmonella spp. have quorum sensing systems mediated by three different classes of autoinducers: AI-1, AI2, and AI-3. AI-1 has been shown to induce biofilm formation by $S$. enteritidis under anaerobic conditions, and an antagonistic structural analog of AI-2, patulin, has been demonstrated to inhibit biofilm formation by quorum quenching (Vijayababu et al., 2018). Quorum sensing inhibitors have also shown promise as potential biofilm dispersing agents, as reviewed by Brackman and Coenye (2014). Therefore, the disruption of various quorum sensing mechanisms may be a promising strategy for the control of biofilm formation and treatment of established biofilms (Giaouris et al., 2015).

Biofilms in poultry and other livestock serve as a source of contamination at nearly every step in the food processing pipeline. Salmonella shed from livestock can infect food workers and will also form biofilms on biotic and abiotic 
surfaces including eggs and meat, but also in processing plants, packaged foods, waste water, and eventually, both commercial and household environments (Lamas et al., 2018). Salmonella biofilms in the food processing pipeline may be controlled through a variety of measures, including proper hygiene standards and use of personal protective equipment for food workers, the use of antibiotics and other antimicrobials in livestock, and physical or chemical sterilization for food processing plants, kitchens, and storage areas (Lamas et al., 2018). However, these measures often fail to eradicate biofilms entirely, allowing for the continuous spread of Salmonella, which may increase the resistance of Salmonella to these treatments. As infected livestock are often the major initial source of Salmonella in other environments, it only makes sense to investigate new approaches for preventing Salmonella infection and the carrierstate in poultry.

As mentioned previously, an increase in the use of antibiotics can lead to antibiotic-resistance as well as disruption of the normal microbial flora, with around 100,000 infections due to antibiotic-resistant Salmonella alone each year (Nair et al., 2018). While salmonellosis typically resolves on its own without treatment, more serious cases may need intervention, which typically involves the use of antibiotic drugs. Common first line treatments for NTS in the United States include fluoroquinolones in adults and azithromycin in children. However, drug resistance and multidrug resistance in Salmonella is now common. For example, in a 2019 outbreak, the Salmonella Infantis strain identified was resistant to, "ciprofloxacin, ceftriaxone, or other antibiotics including ampicillin, chloramphenicol, fosfomycin, gentamicin, kanamycin, nalidixic acid, streptomycin, sulfisoxazole, trimethoprim-

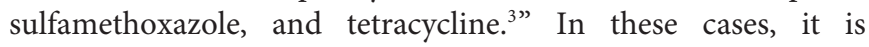
recommended to determine the appropriate antibiotic based on individual antimicrobial susceptibility testing, which is not always possible and can be costly and time consuming. In poultry, antimicrobial treatment for the control of Salmonella is rare and strongly discouraged, requiring veterinary oversight in the US, especially in the case of medically important antimicrobial drugs. In most cases, the negative disease status of flocks is maintained through the eradication of the entire flock if it is found to be harboring Salmonella (Agunos et al., 2012).

Therefore, scientists are now looking at alternative strategies for controlling and treating Salmonella infections. Newer strategies include prophylactic measures, such as the development of vaccines, as reviewed by Desin et al. (2013), or the use of probiotics, prebiotics, and their derivatives, such as fermentates, feed additives, and antimicrobial peptides. The use of probiotics and their derivatives in the control of pathogens and prevention of antimicrobial resistance is a promising alternative to traditional antibiotic treatments. The World Health Organization defines probiotics as "live microorganisms which when administered in adequate amounts confer a health benefit to the host." In addition to their antimicrbioal potential, the presence of probiotics in poultry feed has been shown to improve overall growth and intestinal health, and provide

${ }^{3}$ https://www.cdc.gov/salmonella/infantis-10-18/advice.html other benefits related to meat and egg quality (Popova, 2017; Makarenko et al., 2019). Probiotics can also boost the immune system, stimulate endogenous enzymes, produce antimicrobial substances, and reduce the production of toxic substances by controlling the metabolic pathways for their synthesis. Antimicrobial substances produced by probiotics are also able to inhibit the production of toxins and the adhesion ability of some pathogens (Monteagudo-Mera et al., 2019).

Spore-forming bacteria as probiotics have become more popular in recent years. Spores are dormant bacterial structures that are highly resistant to hostile environmental conditions. Bacterial spores greatly increase the chance of survival when exposed to UV radiation, temperatures of $80-85^{\circ} \mathrm{C}$, various solvents, hydrogen peroxide, and enzymes such as lysozyme. Spores possess notable advantages as probiotics, including storage at room temperature without losing viability, and the ability to safely pass through the gastric bactericidal barrier. When spores find themselves in a less hostile environment, such as the intestines, they germinate and resume vegetative cell growth (Cutting, 2011). B. subtilis are Gram-positive sporeforming bacteria, some of which are used as probiotics in chicken. Studies have shown that B. subtilis spores have the ability to germinate in the gastrointestinal tract of poultry (Cartman et al., 2008).

B. subtilis KATMIRA1933 is a strain isolated from a dairy product that has been shown to have probiotic capacities related to the production of bacteriocins, which are ribosomallysynthesized antimicrobial peptides. They often have a narrow range of activity, and often only target species that are closely related to the bacteriocin producer (Shelburne et al., 2007). Subtilosin A, which is a cyclic peptide, is one of the primary bacteriocins produced by Bacillus subtilis. It has been shown to have antimicrobial activity against a range of bacteria, including Gram-positive, Gram-negative (in the presence of chelating agents), aerobic, and anaerobic species (AlGburi et al., 2016). Subtilosin A is largely hydrophobic and is likely to act in part due to interactions with the hydrophobic portion of the phospholipid bilayer of the cell membrane. Subtilosin A also has a negatively charged region that remains exposed to the outside environment and may act on receptors on the membrane's surface. The antimicrobial activity of subtilosin A against several pathogens, such as Listeria monocytogenes, Gardnerella vaginalis, and Streptococcus agalactiae has been reported (Nikiforova et al., 2016). B. amyloliquefaciens B-1895 is another probiotic with antimicrobial properties. B. amyloliquefaciens B-1895 was originally isolated from a soil sample and has been found to produce a variety of proteolytic enzymes. It also produces the antimicrobial peptide subtilin, which has been shown to have activity against the foodborne pathogen Listeria monocytogenes (Algburi et al., 2020b).

The purpose of this study was to investigate the effects of B. subtilis KATMIRA193s and B. amyloliquefaciens B-1895 and their cell-free supernatants (CFS) on the biofilm formation ability and planktonic cell viability of pathogenic Salmonella species. Both strains harbor the genes coding for antimicrobials (Karlyshev et al., 2014a,b) and are probiotic microorganisms promoting the health of poultry (Prazdnova et al., 2019). 


\section{MATERIALS AND METHODS}

\section{Bacterial Culture and Growth Condition: B. subtilis KATMIRA1933 and B. amyloliquefaciens B-1895}

Streak plates of B. subtilis KATMIRA1933 and B. amyloliquefaciens B-1895 were made using DeMan, Rogosa, and Sharpe agar (MRS, BD Difco, Franklin Lakes, NJ, United States) from frozen stock maintained in the Health Promoting Naturals Laboratory collection at $-80^{\circ} \mathrm{C}$. The plates were incubated aerobically at $37^{\circ} \mathrm{C}$ for $24 \mathrm{~h}$. A single colony was picked from each plate and inoculated into MRS broth in $15 \mathrm{~mL}$ conical centrifuge tubes (Corning, Corning, NY, United States). The tubes were incubated at $37^{\circ} \mathrm{C}$ for $18 \mathrm{~h}$ and were tilted at 45 degrees in order to increase the surface area for maximum aeration. Two subsequent subcultures of 1:100 dilutions were made under the same conditions.

\section{Antibacterial Activity of Individual Colonies of $B$. subtilis KATMIRA1933 and B. amyloliquefaciens B-1895 Against Micrococcus luteus ATCC 10420}

The reference strain Micrococcus luteus ATCC 10240 is commonly used for the testing of bacteriocins' antimicrobial activity (Mauriello et al., 2005). The microorganism was obtained from the American Type Culture Collection (ATTC, Manassas, Virginia, United States). A subculture of M. luteus was streaked on MRS agar and incubated at $37^{\circ} \mathrm{C}$ for $24 \mathrm{~h}$. Ten single colonies of B. subtilis KATMIRA1933 and B. amyloliquefaciens B-1895 were selected and then plated on two different sets of MRS agar to obtain replicate plates. The plates were incubated at $37^{\circ} \mathrm{C}$ for $18 \mathrm{~h}$. One of the plates was treated with chloroform vapor in a biosafety cabinet (SG 400, The Baker Company, Sanford, Maine, United States) for $60 \mathrm{~min}$ to kill the cells. A piece of filter paper was placed on the lid of the petri dish and $2 \mathrm{~mL}$ of chloroform was added to it every $20 \mathrm{~min}$, with the agar plate placed upside down above the lid during treatment. A soft agar overlay test was used to identify single colonies with the best production of antimicrobials, as determined by a comparison of the diameters of the observed zones of inhibition for each colony. Two milliliter of soft agar seeded with $100 \mu \mathrm{L}$ of $10^{6} \mathrm{CFU} / \mathrm{mL}$ M. luteus ATCC 10240 was poured onto the chloroform-treated plate. The treated plates were incubated at $37^{\circ} \mathrm{C}$ for $24 \mathrm{~h}$, and the untreated plates were kept at $4^{\circ} \mathrm{C}$. The colony with the largest zone of inhibition was selected for each strain. The corresponding untreated colony was then streaked, and the same procedure was performed again. The experiment was repeated three times in order to obtain the best and most consistent antimicrobial producing colony for both strains. Frozen stocks (1:1 solution of 50\% glycerol in water together with overnight growth in MRS broth) were made from the colonies for further experiments.

\section{Salmonella and Bacilli Cross Test}

A cross-test was performed to assess the potential antagonistic activity of the two bacilli on Salmonella when grown on solid media. The cross test was performed according to Balouiri et al. with some modifications (Balouiri et al., 2016). Two vertical lines of $10^{6} \mathrm{CFU} / \mathrm{mL}$ B. subtilis KATMIRA1933 or B. amyloliquefaciens B-1895 were streaked $5 \mathrm{~cm}$ apart on a TSA plate using an inoculation loop (BD Difco, Franklin Lakes, NJ, United States), and the plates were left to dry for $10 \mathrm{~min}$. Then, a horizontal line of $10^{6} \mathrm{CFU} / \mathrm{mL}$ Salmonella species (Thompson, Enteritidis phage type 4, and Hadar) was streaked perpendicular to the bacilli streaks by an inoculation loop. The plates were incubated at $37^{\circ} \mathrm{C}$ for $24 \mathrm{~h}$. Then, they were kept in a biosafety cabinet at room temperature for an additional 3 days.

In a second experiment, two vertical lines of $10^{6} \mathrm{CFU} / \mathrm{mL}$ B. subtilis KATMIRA1933 or B. amyloliquefaciens B-1895 were streaked $5 \mathrm{~cm}$ apart on a TSA plate using an inoculation loop, and the plates were incubated at $37^{\circ} \mathrm{C}$ for $24 \mathrm{~h}$. Then, the Salmonella species were streaked as in the previous experiment. The plates were incubated at $37^{\circ} \mathrm{C}$ for $24 \mathrm{~h}$ and were kept in the hood for an additional 3 days.

\section{Salmonella and Bacilli Co-culture}

A co-culture experiment was performed to assess the potential antagonistic activity of the two bacilli on the viability of Salmonella when grown in liquid medium. Overnight cultures of Salmonella and bacilli were prepared. One hundred microliter of the overnight cultures was added to $9.9 \mathrm{~mL}$ of TSB in order to dilute the samples to $10^{7} \mathrm{CFU} / \mathrm{mL}$. One hundred $\mu \mathrm{L}$ of diluted Salmonella and $100 \mu \mathrm{L}$ of diluted bacilli were inoculated in $9.8 \mathrm{~mL}$ of TSB in order to prepare the mixed culture. For the positive control, $100 \mu \mathrm{L}$ of diluted sample was inoculated in $9.9 \mathrm{~mL}$ of TSB. The cultures were incubated for 24 and $48 \mathrm{~h}$ at $37^{\circ} \mathrm{C}$, with agitation at $180 \mathrm{rpm}$. One hundred $\mu \mathrm{L}$ of the mixed cultures and the positive controls was spread on XLT-4 agar (BD Difco, Franklin Lakes, NJ, United States). The plates were incubated at $37^{\circ} \mathrm{C}$ for $16 \mathrm{~h}$ and colonies were then enumerated to assess Salmonella viability.

\section{Preparation of CFS of the Selected Bacilli Colonies}

The selected colonies were inoculated in MRS broth and subcultured three times at $37^{\circ} \mathrm{C}$ for $18 \mathrm{~h}$ with agitation at $185 \mathrm{rpm}$, and the tubes were tilted at 45 degrees during incubation. The third subculture was transferred to an Eppendorf tube (Eppendorf, Hamburg, Germany) and was centrifuged at $16000 \mathrm{~g}$ for $5 \mathrm{~min}$. The supernatant was filter-sterilized using Millex $0.22 \mu \mathrm{m}$ non-pyrogenic filters (Merck Millipore Ltd., Co., Cork, Ireland). The $\mathrm{pH}$ of the CFS was measured after filter-sterilization and compared against an MRS control.

\section{Antimicrobial Activity of the Bacilli CFS}

A lawn culture from a 1:100 dilution $\left(10^{6} \mathrm{CFU} / \mathrm{mL}\right)$ of overnight grown M. luteus was made on tryptic soy agar plates (TSA, BD Difco, Franklin Lakes, NJ, United States). Four $5 \mathrm{~mm}$ holes were punched using the wide ed of sterile $200 \mu \mathrm{L}$ pipette tips, and the agar was removed in order to make four wells on the plate. Then, $100 \mu \mathrm{L}$ of CFS of either B. subtilis KATMIRA1933 or B. amyloliquefaciens B-1895 (producing subtilosin A and subtilin 
respectively) was added to three of the wells. Afterward, $100 \mu \mathrm{L}$ of MRS broth was added to the fourth well as a negative control. The plates were left under the hood until the diffusion was complete. When the wells had dried, the plates were then incubated at $37^{\circ} \mathrm{C}$ for $24 \mathrm{~h}$. This experiment was repeated three times.

\section{Salmonella Biofilm Inhibition Assay}

Biofilm formation by five strains of Salmonella (Thompson, Enteritidis phage type 13a, Enteritidis phage type 4, Typhimurium phage type DT104, Hadar) was tested using flat and round bottom tissue-culture treated Falcon 96 and 48 well plates (Corning, Corning, NY, United States). 1:10 and 1:100 dilutions of $10^{6} \mathrm{CFU} / \mathrm{mL}$ were prepared using TSA with $1 \%$ glucose. The incubation temperature was $37^{\circ} \mathrm{C}$, and the incubation times were 18,24 , and $48 \mathrm{~h}$.

The ability of the bacteriocin containing supernatants to inhibit biofilm formation of Salmonella was tested by mixing $100 \mu \mathrm{L}$ of supernatant with $100 \mu \mathrm{L}$ of a 1:10 dilution of $10^{6} \mathrm{CFU} / \mathrm{mL}$ Salmonella in $2 \mathrm{x}$ TSB at $2 \%$ glucose to make the final concentration $1 \%$ in the wells. The 96 well plates were incubated at $37^{\circ} \mathrm{C}$ for $24 \mathrm{~h}$.

Quantitative analysis of inhibition of biofilm formation was done using the crystal violet (CV) staining assay. After a 24 $\mathrm{h}$ incubation period, planktonic cells were removed from each well by a $200 \mu \mathrm{L}$ pipette. The planktonic cells of the first three wells of each column were transferred to a new 96 well plate for spot plating. The wells were then gently washed three times with $200 \mu \mathrm{L}$ of phosphate-buffered saline (PBS, Fisher BioReagents, Pittsburg, Pennsylvania, United States). The biofilm was fixed by heating at $60^{\circ} \mathrm{C}$ for $60 \mathrm{~min}$ and stained with $\mathrm{CV}$, according to Borucki et al., 2003. One hundred twenty-five microliter of $0.1 \%$ $\mathrm{CV}$ was added over the biofilm and left at room temperature $\left(23-25^{\circ} \mathrm{C}\right)$ for $20 \mathrm{~min}$. Each well was then rinsed 3-4 times with $200 \mu \mathrm{l}$ of distilled water and left for $15 \mathrm{~min}$ to dry at room temperature. One hundred microliter of $95 \%$ (v/v) ethanol in water was added into each well to solubilize the $\mathrm{CV}$-stained biofilm. The plate was then incubated at $4^{\circ} \mathrm{C}$ for $30 \mathrm{~min}$. After incubation, $100 \mu \mathrm{L}$ of solution was then transferred from each well into a second 96 well plate. An absorbance measurement was made using an Automated Absorbance reader at $595 \mathrm{~nm}$ (Diagnostic Automation, Woodland Hills, CA, United States).

\section{Enumerating the Cells in Planktonic Cultures by Spot Plating}

Spot plating was performed according to Gaudy et al. (1963). Nine hundred microliter of TSB was added to the wells of a sterile deep well plate. One hundred microliter of the planktonic cells, from the $24 \mathrm{~h}$ growth of the Salmonella with bacilli supernatants, was added to the first well. Seven subsequent 1:10 dilutions were made. Twenty microliter of each diluted solution was spot plated on a TSA plate. The plates were incubated at $37^{\circ} \mathrm{C}$ for $16 \mathrm{~h}$, and the colonies for each spot were then counted.

\section{Statistical Analysis}

All experiments were conducted a minimum of three times in duplicate. The error bars in the provided figures represent the standard deviations of the data. All calculations were performed in Microsoft Excel, and then the statistical analysis was reshaped with SigmaPlot 11.0 (Systat Software Inc., Chicago, IL, United States). The Student t test and Mann-Whitney Rank Sum Test was also performed using SigmaPlot 11.0.

\section{RESULTS}

\section{Antibacterial Activity of Single Colonies of $B$. subtilis KATMIRA1933 and B. amyloliquefaciens B-1895 Against M. Iuteus ATCC 10240}

The colonies with the best inhibitory activity were selected for further experiments. On the third re-culturing, the zone of inhibition of the best performing B. subtilis KATMIRA1933 $B$. and amyloliquefaciens B-1895 colonies were 11 and $10 \mathrm{~mm}$, respectively.

\section{Salmonella and Bacilli Cross Test}

After a $24 \mathrm{~h}$ incubation period, no Salmonella inhibition was observed with the cross tests. The plates were kept under the hood for an additional $72 \mathrm{~h}$ at room temperature. Again, no Salmonella inhibition was detected, indicating that there is not direct inhibtion of Salmonella growth by the two bacilli and their metabolites.

\section{Salmonella and Bacilli Co-culture}

Figure 1 shows the effects of co-culturing of $B$. subtilis KATMIRA1933 and B. amyloliquefaciens B-1895 on the Salmonella cell count after a 24 and $48 \mathrm{~h}$ incubation period. The CFU/ml of the positive control, the mixture with $B$. subtilis KATMIRA1933, and the mixture with B. amyloliquefaciens B1895 after $24 \mathrm{~h}$ was $52.53 \times 10^{10}, 1.67 \times 10^{10}$, and $1.73 \times 10^{10}$ for Salmonella Hadar, $2.20 \times 10^{10}, 2.00 \times 10^{10}$, and $1.73 \times 10^{10}$ for Salmonella Enteritidis phage type 4, and $5.33 \times 10^{9}, 6.72 \times 10^{9}$, and $6.65 \times 10^{9}$ for Salmonella Thompson, respectively. The $\mathrm{CFU} / \mathrm{ml}$ of the positive control, the mixture with $B$. subtilis KATMIRA1933, and the mixture with the B. amyloliquefaciens B-1895 after $48 \mathrm{~h}$ was $8.81 \times 10^{9}, 7.8 \times 10^{9}$, and $8.53 \times 10^{9}$, and $1.73 \times 10^{10}$ for Salmonella Hadar, $2.8 \times 10^{9}, 4.1 \times 10^{9}$, and $3.3 \times 10^{9}$ for Salmonella Enteritidis phage type 4 , and $3.7 \times 10^{8}$, $4.0 \times 10^{9}$, and $3.2 \times 10^{8}$ for Salmonella Thompson, respectively. These results indicate that there is no significant inhibtion of the growth of planktonic Salmonella by the bacilli and their metabolites in a liquid environment.

\section{Antimicrobial Activity of the Bacilli CFS}

The average zone of inhibition of the wells containing the B. subtilis KATMIRA1933 CFS was $9 \mathrm{~mm}$, and the average zone of inhibition of the wells containing the $B$. amyloliquefaciens B-1895 was $7 \mathrm{~mm}$. The diameter of the wells was $5 \mathrm{~mm}$. No Bacillus growth was observed on the plates. The average $\mathrm{pH}$ of the tested CFS was $5.83 \pm 0.07$ and $5.85 \pm 0.01$ for B. subtilis KATMIRA1933 and B. amyloliquefaciens B-1895, respectively, as compared to a negative control (MRS medium) at 6.5. 


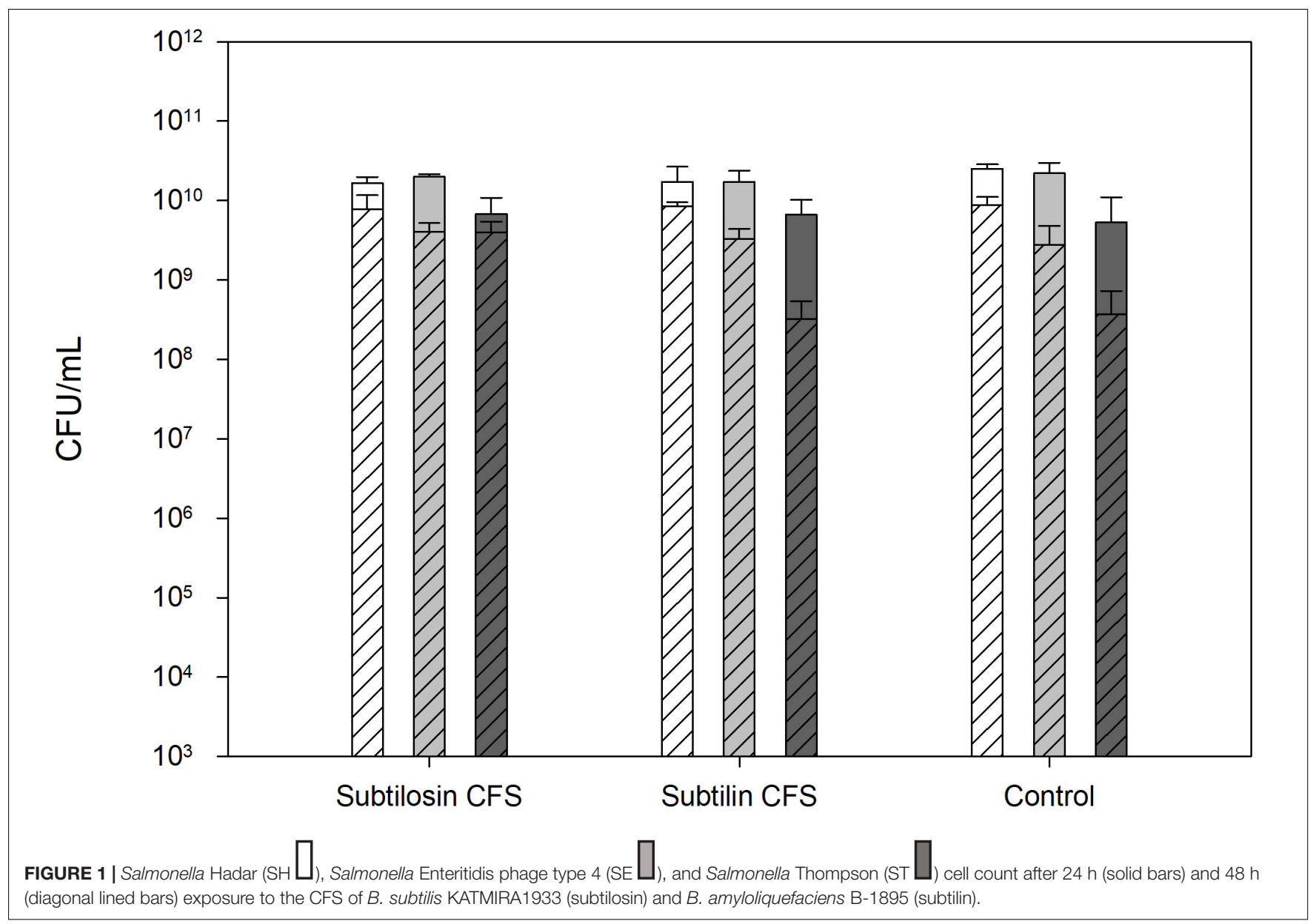

\section{Salmonella Biofilm Formation}

Salmonella Thompson, Enteritidis phage type 4, and Hadar formed the best biofilm, as determined by relative biomass via crystal violet staining, under the following conditions: $24 \mathrm{~h}$ incubation, 1:10 dilution, in round bottom 96 well plates (data not shown).

\section{Biofilm Inhibition and Enumerations of Planktonic Cells}

Figures 2-4 show the effect of the bacilli CFS on Salmonella biofilms and the planktonic cell count for each strain tested. When incubated with B. subtilis KATMIRA1933 CFS, biofilm formation of Salmonella Hadar, Salmonella Enteritidis phage type 4, and Salmonella Thompson was inhibited by $51.1 \%(P=0.001)$, 48.3\% ( $P=0.001)$, and 56.9\% $(P=0.001)$, respectively. When incubated with $B$. amyloliquefaciens B-1895 CFS, the biofilm formation of Salmonella Hadar, Salmonella Enteritidis phage type 4, and Salmonella Thompson was inhibited by $30.4 \%(P=0.001)$, 28.6\% $(P=0.001)$, and $35.5 \%(P=0.001)$, respectively.

The planktonic cell count of the positive control, incubation with B. subtilis KATMIRA1933 CFS, and incubation with the B. amyloliquefaciens B-1895 CFS was $2.9 \times 10^{9}, 2.28 \times 10^{9}$, and $2.52 \times 10^{9}$ for Salmonella Hadar, $3.99 \times 10^{9}, 3.4 \times 10^{9}$, and $4.49 \times 10^{9}$ for Salmonella Enteritidis phage type 4, and $5.24 \times 10^{8}, 4.88 \times 10^{8}$, and $3.6 \times 10^{8}$ for Salmonella Thompson. Therefore, the number of planktonic cells was not affected by the treatment.

\section{DISCUSSION}

In this study, it was shown that B. subtilis KATMIRA1933 and B. amyloliquefaciens B-1895 have potential antimicrobial activity against Salmonella through inhibition of biofilm formation ability, which may result in decreased persistence of the pathogen. This points to the rational replacement of antibiotics for the reduction of salmonella in poultry by probiotics whose mode of action is both natural and presents minimal risk of possible complications, particularly compared to the use of antibiotics and the associated risk of increased antibiotic resistance.

Antibiotic resistance in Salmonella serotypes was first recognized in the 1960 s with the discovery of Salmonella resistant to chloramphenicol, and the number and frequency of isolated resistant and multidrug-resistant strains has continued to increase ever since (Montville and Matthews, 2008). Multidrug resistance in Salmonella is defined as resistance toward firstgeneration antibiotics such as ampicillin, chloramphenicol, 


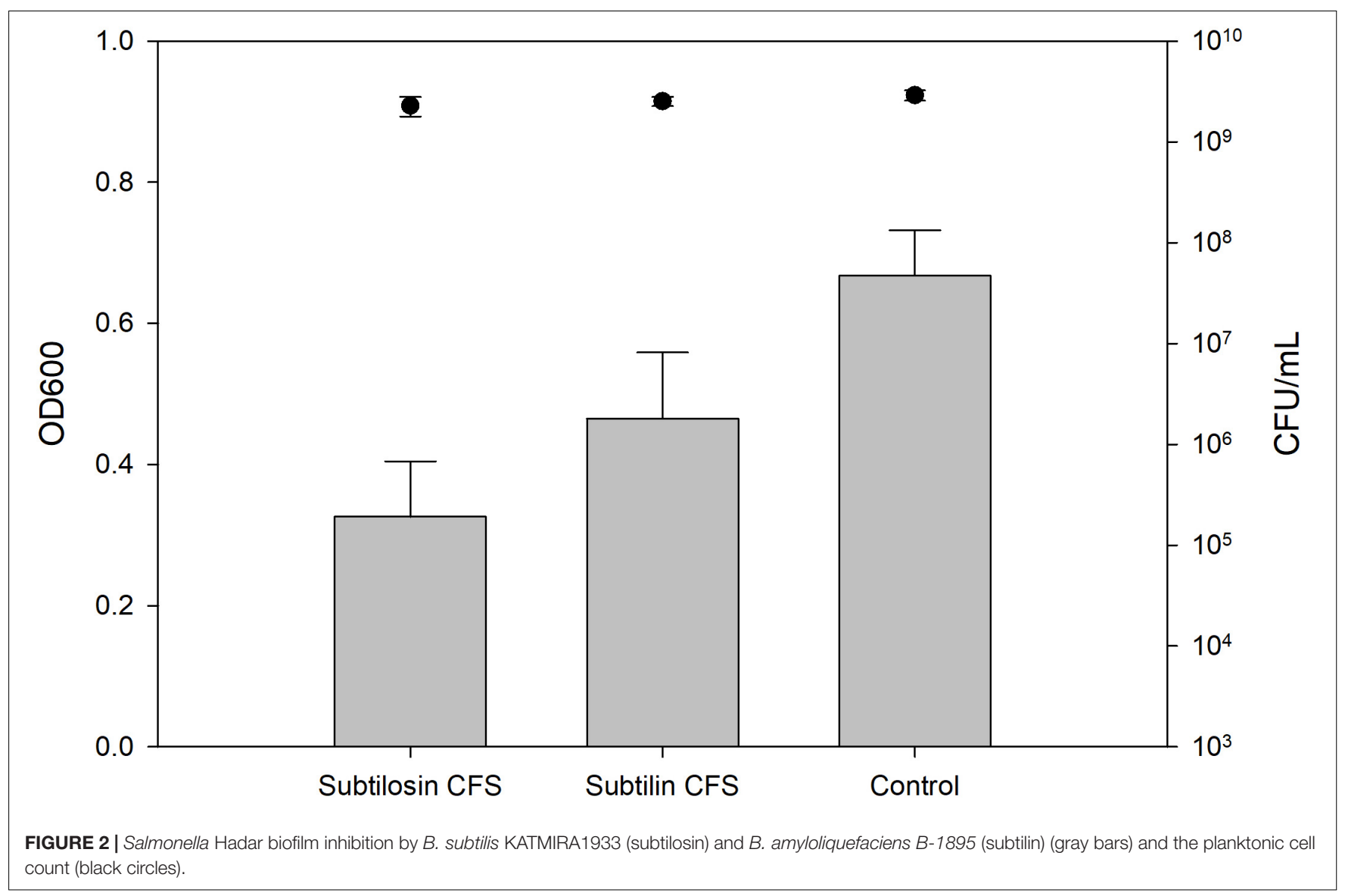

and trimethoprim-sulfamethoxazole. However, an increasing prevalence of MDR Salmonella resistant toward clinically important antimicrobials such as fluoroquinolones and thirdgeneration cephalosporins highlights a worrying trend toward Salmonella infections that are increasingly difficult to treat with antibiotics (Jajere, 2019). Lately, there has been growing interest in research focused on utilizing the antimicrobial properties of probiotics against many pathogens, including multidrugresistant species and strains, with a particular focus on the food, medical, and veterinary industries. In these industries, the uncontrolled and commonplace use of antibiotic regimens greatly increases the chances of resistance development (O'Bryan et al., 2018; Mulani et al., 2019). B. subtilis KATMIRA1933 and B. amyloliquefaciens B-1895 are two bacilli that have exhibited notable antimicrobial potential and have been demonstrated as beneficial and safe for use as probiotics in poultry (Sutyak et al., 2008; Chistyakov et al., 2015; AlGburi et al., 2016). Poultry species are a common reservoir of Salmonella, and as backyard farming becomes more popular, the number of cases of poultry-to-human transmission of salmonellosis is increasing (McDonagh et al., 2019). This increase highlights the importance of developing novel methods for controlling Salmonella infections in poultry that do not carry the same risk of antibiotic resistance development as common antibiotics. Antibiotics are known to alter the composition of microbial flora, often leading to dysbiosis and increased susceptibility of the host to enteric infections by irrational use. The intestinal microbiota plays a key role in maintaining a healthy intestinal environment through various means, such as increasing nutrient availability, modulating the host immune system, and through competitive and antagonistic interactions with pathogens. One of the crucial defense mechanisms of commensal bacteria is to prevent biofilm formation by invasive or opportunistic pathogens (Vuotto et al., 2014). There has been some evidence suggesting that oral consumption of probiotics might decrease the colonization of the GIT by Salmonella in chickens. Studies have specifically shown the importance of Bacillus subtilis in decreasing the chances of Salmonella causing disease (Hayashi et al., 2018).

In order to determine the potential antimicrobial activity of B. subtilis KATMIRA1933 and B. amyloliquefaciens B-1895 against pathogenic salmonellae, single colonies of these two strains were killed to make sure that any observed inhibition of the common indicator strain, M. luteus ATCC 10420, was due to the cellular products of these two strains. This experiment was repeated three times in order to produce colonies with the best antimicrobial activity. The selected colonies were then used for the production of CFS. The antimicrobial activity of CFS was again checked against $M$. luteus ATCC 10420, thereby confirming the presence and activity of bacteriocins in the supernatant. The antimicrobial potential of the of the two bacilli against Salmonella was assayed using both a cross test and bacterial co-culture method. Both experiments showed no significant inhibition of 


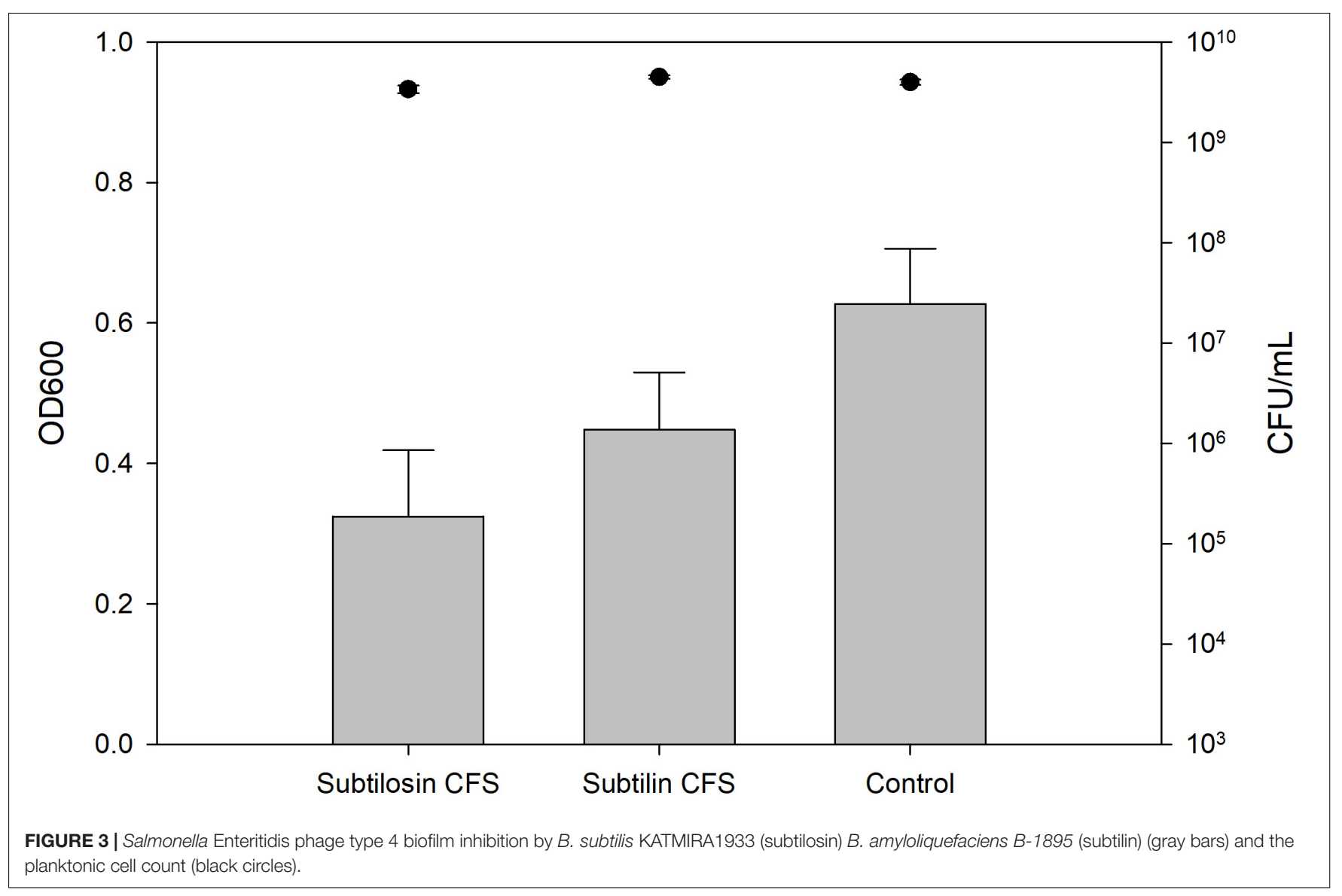

Salmonella growth due to the presence of the bacilli when grown on solid or liquid media. These results indicate that any observed inhibition of biofilm is likely not due to direct inhibition or killing but is instead due to other mechanisms.

The biofilm formation ability of the three Salmonella strains was affected more by $B$. subtilis KATMIRA1933 CFS than B. amyloliquefaciens B-1895 CFS. The CFS of B. subtilis KATMIRA1933 inhibited biofilm formation of the three salmonellae by approximately 50\%, while the CFS of B. amyloliquefaciens B-1895 inhibited biofilm formation by about $30 \%$. This degree of inhibition is not dissimilar from the antibiofilm activity of the two strains against MRSA and MSSA, where 25-50\% concentrations of CFS were found to inhibit biofilm formation by $45-59 \%$ (Algburi et al., 2020a). The antibiofilm activity of the two strains has also been determined for Proteus mirabilis isolated from urinary tract infections, where even greater inhibition was seen, with $72-84 \%$ inhibition recorded in that study (Algburi et al., 2020b). Interestingly, while the CFS of the two bacilli were found to be effective in inhibiting the biofilm formation in Gram-positive S. aureus and P. mirabilis, they have now been shown to prevent biofilm formation in Gramnegative Salmonella. This is in contrast to the antimicrobial activity of the two probiotics and their CFS against planktonic cells, where they are effective against Gram-positive species, but generally ineffective against Gram-negative species such as E. coli, $P$. aeruginosa, and E. aerogenes (Huang et al., 2009).
The number of planktonic cells of the three Salmonella serovars was not influenced by treatment with either CFS. The 24 and $48 \mathrm{~h}$ co-culture experiments also showed that the number of viable cells of the Salmonella strains is not significantly altered when grown together with B. subtilis KATMIRA1933 or B. amyloliquefaciens B-1895. These results, together with previous findings, point toward the possibility of a separate mode of action for the observed anti-biofilm activity that is not necessarily linked to the observed antimicrobial activity of the two strains, nor is it related to direct cell-to-cell contact or co-aggregation.

There are several possible explanations for the observed activity of the CFS, which may be related to the activity of one or more substances produced by the two bacilli, such as subtilosin $\mathrm{A}$ and subtilin, or other potential bioactive compounds, such as weak organic acids, enzymes, or bacteriocinlike inhibitory substances (BLIS). Other probiotics have shown that antimicrobial activity against Salmonella is linked to a low $\mathrm{pH}$ and the production of lactic acid. For example, it has been shown that the antimicrobial activity of Lactobacillus rhamnosus GG against Salmonella typhimurium is mediated by lactic acid, as confirmed by the antimicrobial activity of L. rhamnosus supernatant as compared to a $\mathrm{pH}$ matched $\mathrm{HCl}$ acid control. However, the activity was found to be $\mathrm{pH}$ depended, with a maximum at $\mathrm{pH} 4.5$ and an absence of antimicrobial activity at pH 6.6 (De Keersmaecker et al., 2006). Unlike lactic acid bacteria, 


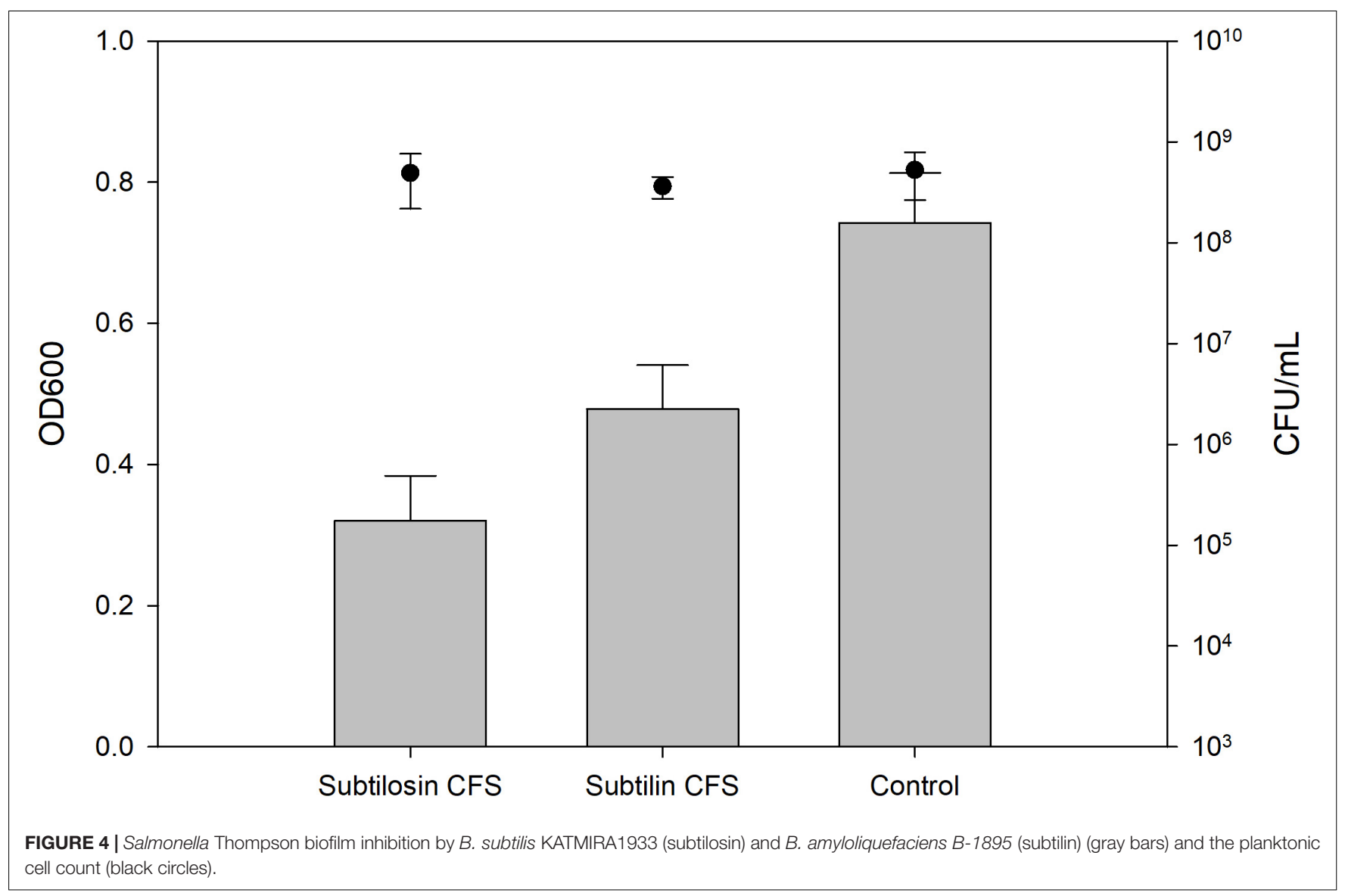

sporeforming bacilli produce modest concentrations of lactic acid (10-40 mM), with a moderate decrease of $\mathrm{pH}$ from neutral to about 6.5. Noticeably, an engineered strain B. subtilis MUR1 is producing up to $2 \mathrm{M}$ of L-lactic acid after $52 \mathrm{~h}$ of fermentation (Ohara and Yahata, 1996; Fry et al., 2000).

Under the conditions used in for the cultivation of B. subtilis KATMIRA1933 or B. amyloliquefaciens B-1895 in this manuscript, there was no significant lactic acid production, as the $\mathrm{pH}$ was not controlled for during the $24 \mathrm{~h}$ incubation period, with a resulting drop in $\mathrm{pH}$ from 6.5 to $5.83 \pm 0.07$ and $5.85 \pm 0.01$, respectively. As the antimicrobial activity of lactic acid against Salmonella is $\mathrm{pH}$ dependent, the effect of lactic acid in this experiment is likely minimal.

Subtilosin has previously been reported to prevent biofilm formation of Gram-variable G. vaginalis by inhibiting quorum sensing via a reduction in the production of autoinducer-2 (AI2). However, in the same study, subtilosin was shown to inhibit biofilm formation of Listeria monocytogenes without influencing AI-2 production (AlGburi et al., 2016). Similar results have been found with other bacteriocins, including lactocin AL705, which inhibits biofilm formation at sub-MIC concentrations without reducing the production of an AI-2 like molecule in L. monocytogenes, as recognized by a $V$. vibrio reporter strain (Melian et al., 2019). Evidence in the literature on the influence of luxS/AI-2 in biofilm formation is inconclusive, and findings cannot be translated from one species to another.
A Haemophilus parasuis $\Delta$ luxS strain had decreased production of AI-2 molecules compared to the wild type and displayed decreased adherence while at the same time having increased abilities to form biofilm in vitro (Zhang et al., 2019). In a different study involving an $S$. epidermis $\Delta$ luxS mutant, luxS was found to repress biofilm formation through a cell-cell signaling mechanism based on autoinducer 2 secretion (Xu et al., 2006). Transcriptomic and phenotypic studies on biofilm formation in a Salmonella enterica Serovar Typhimurium $\Delta l u x S$ mutant found that biofilm formation was significantly less in the $\Delta$ luxS mutant, demonstrating the potential importance of luxS/AI-2 for biofilm formation in salmonellae (Jesudhasan et al., 2010). In order to confirm whether the observed biofilm inhibition in this study is linked to inhibition or interference with luxS/AI-2 signaling, further experiments with the purified bacteriocins and $\Delta l u x S$ Salmonella enterica serovars will be necessary.

The observed antibiofilm activity may be related to other bacterial communication systems, such as the AI-1 and AI-3 signaling pathways, both of which are present in Salmonella. It is also possible that the anti-biofilm activity may be completely unrelated to quorum sensing inhibition and may instead be the consequence of more direct interactions. Both strains produce a variety of proteolytic enzymes, including several subtilisin or peptidase S8 family subtilisin-related serine proteases, that may have potential use in both treating and preventing biofilms 
(Karlyshev et al., 2014a,b). This family of enzymes is produced by Bacillus spp. and able to hydrolyze adhesins that are necessary for proper bacterial aggregation and biofilm formation. Protease treatment has been shown to impact invasion ability, and biofilm formation in L. monocytogenes (Longhi et al., 2008), and subtilisin treatment has been used to destroy Staphylococcus epidermidis and Staphylococcus aureus biofilms (Elchinger et al., 2014). To better understand the mechanisms responsible for the observed biofilm inhibition, the antibiofilm activity of CFS and purified compounds of interest (subtilosin A, subtilin, subtilisinrelated serine proteases, lactic acid) should be investigated, and potential quorum sensing activities confirmed through the use of mutant knockouts for the relevant genes in salmonellae of interest.

B. subtilis KATMIRA1933 and B. amyloliquefaciens B-1895 have been shown to have different modes of activity in poultry. Previous studies reported that when used as probiotics in poultry, they have different impacts on the quality of rooster sperm production, egg production, hatching egg quality, egg hatchability, etc. (Mazanko et al., 2018). Interestingly, when used in combination, these two strains are antagonists. For instance, use of B. subtilis KATMIRA1933 alone shows an increase in vitellogenin gene expression levels, resulting in the stabilization of mitochondrial DNA by decreasing relative damage, slowing down reproductive aging, and potentially improving egg-laying ability. The use of a combination of the two species resulted in a decrease in the observed positive effects (Mazanko et al., 2019; Prazdnova et al., 2019). One possible explanation for this phenomenon is that the metabolites of these two probiotic strains have a similar pharmacodynamic mode of action with the same molecular targets.

The main challenge of salmonellosis is in its zoonotic potential, as most animal reservoirs are asymptomatically infected, creating suitable conditions for horizontal and vertical paths of transmission, resulting in the presence of Salmonella spp. in up to 65\% of birds in a flock (Chlebicz and Śliżewska, 2018). This, in turn, makes it easier for pathogenic bacteria to invade a wide environmental area following human contamination through consumption of livestock and agricultural products (Wiedemann et al., 2014; Kurtz et al., 2017). Salmonellosis

\section{REFERENCES}

Agunos, A., Léger, D., and Carson, C. (2012). Review of antimicrobial therapy of selected bacterial diseases in broiler chickens in Canada. Can. Vet. J. 53, 1289-1300.

Ajmera, A., and Shabbir, N. (2020). 'Salmonella', in StatPearls [Internet]. Treasure Island (FL): StatPearls Publishing

Akil, L., and Ahmad, H. A. (2019). Quantitative Risk Assessment Model of Human Salmonellosis Resulting from Consumption of Broiler Chicken. Diseases 7:19. doi: 10.3390/diseases7010019

Algburi, A., Al-Hasani, H. M., Ismael, T. K., Abdelhameed, A., Weeks, R., Ermakov, A. M., et al. (2020a). Antimicrobial Activity of Bacillus subtilis KATMIRA1933 and Bacillus amyloliquefaciens B-1895 Against Staphylococcus aureus Biofilms Isolated from Wound Infection. Probiot. Antimicrob. Proteins 2020, 9673-9674. doi: 10.1007/s12602-020-09673-4

Algburi, A., Alazzawi, S. A., Al-Ezzy, A. I. A., Weeks, R., Chistyakov, V., and Chikindas, M. L. (2020b). Potential Probiotics Bacillus subtilis KATMIRA1933 and Bacillus amyloliquefaciens B-1895 Co-Aggregate with Clinical Isolates of a multifactorial infection requiring an integrated approach, and finding appropriate probiotic bacteria may help solve this problem, as they do not require major financial expenseswhen compared to the routine and irrational use of antibiotic therapy and prophylaxis in both the healthcare and agricultural industries (Wang et al., 2019b).

In this paper, it is shown that B. subtilis KATMIRA1933 and B. amyloliquefaciens B-1895 inhibit biofilm formation of several Salmonella serovars, which points to the high potential of using these bacilli strains as probiotics not only as a beneficial feed additive for poultry with the goal of increasing their physiological parameters, but as effective antimicrobial producers and prophylactic agents against Salmonella as well. These beneficial properties highlight the high potential of these probiotics for use in poultry resulting in greater economic gain, reduced environmental impact, and improved public health.

\section{DATA AVAILABILITY STATEMENT}

The raw data supporting the conclusions of this article will be made available by the authors, without undue reservation.

\section{AUTHOR CONTRIBUTIONS}

MT conducted experiments, collected data and conducted the primary data analysis and was responsible for drafting and finalizing the report. All authors contributed equally to the manuscript.

\section{FUNDING}

IP, AE, VC, and MC were supported by the Ministry of Science and Higher Education of the Russian Federation (Project Number 075-15-2019-1880). EP was supported by the Ministry of Science and Higher Education of the Russian Federation within the framework of the state task in the field of scientific activity (Southern Federal University, No. 0852-2020-0029).

Proteus mirabilis and Prevent Biofilm Formation. Probiot. Antimicrob. Proteins 2020, 9631-9630. doi: 10.1007/s12602-020-09631-0

AlGburi, A., Volski, A., Cugini, C., Walsh, E. M., Chistyakov, V. A., Mazanko, M. S., et al. (2016). Safety Properties and Probiotic Potential of Bacillus subtilis KATMIRA1933 and Bacillus amyloliquefaciens B-1895. Adv. Microbiol. 06, 432-452. doi: 10.4236/aim.2016.66043

Balouiri, M., Sadiki, M., and Ibnsouda, S. K. (2016). Methods for in vitro evaluating antimicrobial activity: A review. J. Pharm. Anal. 6, 71-79. doi: 10.1016/j.jpha. 2015.11.005

Bertelloni, F., Tosi, G., Massi, P., Fiorentini, L., Parigi, M., Cerri, D., et al. (2017). Some pathogenic characters of paratyphoid Salmonella enterica strains isolated from poultry. Asian Pac. J. Trop. Med. 10, 1161-1166. doi: 10.1016/j.apjtm.2017. 10.023

Borucki, M. K., Peppin, J. D., White, D., Loge, F., and Call, D. R. (2003). Variation in biofilm formation among strains of Listeria monocytogenes. Appl. Environ. Microbiol. 69, 7336-7342. doi: 10.1128/AEM.69.12.7336-7342.2003

Brackman, G., and Coenye, T. (2014). Quorum Sensing Inhibitors as Anti-Biofilm Agents. Curr. Pharm. Des. 21, 5-11. doi: 10.2174/1381612820666140905114627 
Cartman, S. T., La Ragione, R. M., and Woodward, M. J. (2008). Bacillus subtilis spores germinate in the chicken gastrointestinal tract. Appl. Environ. Microbiol. 74:5254. doi: 10.1128/AEM.00580-08

Chistyakov, V., Melnikov, V., Chikindas, M. L., Khutsishvili, M., Chagelishvili, A., Bren, A., et al. (2015). Poultry-beneficial solid-state Bacillus amyloliquefaciens B-1895 fermented soybean formulation. Biosci. Microb. Food Heal. 34, 25-28. doi: 10.12938/bmfh.2014-012

Chlebicz, A., and Śliżewska, K. (2018). Campylobacteriosis, Salmonellosis, Yersiniosis, and Listeriosis as Zoonotic Foodborne Diseases: A Review. Int. J. Environ. Res. Public Health. 15:863. doi: 10.3390/ijerph15050863

Cutting, S. M. (2011). Bacillus probiotics. Food Microbiol. 28, 214-220. doi: 10. 1016/j.fm.2010.03.007

De Keersmaecker, S. C., Verhoeven, T. L., Desair, J., Marchal, K., Vanderleyden, J., and Nagy, I. (2006). Strong antimicrobial activity of Lactobacillus rhamnosus GG against Salmonella typhimurium is due to accumulation of lactic acid. FEMS Microbiol. Lett. 259, 89-96. doi: 10.1111/j.1574-6968.2006.00250.x

Dekker, J. P., and Frank, K. M. (2015). Salmonella, Shigella, and Yersinia. Clin. Lab. Med. 35, 225-246. doi: 10.1016/j.cll.2015.02.002

Desin, T. S., Köster, W., and Potter, A. A. (2013). Salmonella vaccines in poultry: past, present and future. Exp. Rev. Vac. 12, 87-96. doi: 10.1586/erv.12.138

Eade, C. R., Bogomolnaya, L., Hung, C. C., Betteken, M. I., Adams, L. G., AndrewsPolymenis, H., et al. (2019). Salmonella pathogenicity island 1 is expressed in the chicken intestine and promotes bacterial proliferation. Infect. Immun. 87, e503-e518. doi: 10.1128/IAI.00503-18

Elchinger, P. H., Delattre, C., Faure, S., Roy, O., Badel, S., Bernardi, T., et al. (2014). Effect of proteases against biofilms of Staphylococcus aureus and Staphylococcus epidermidis. Lett. Appl. Microbiol. 59, 507-513. doi: 10.1111/lam.12305

Fàbrega, A., and Vila, J. (2013). Salmonella enterica serovar Typhimurium skills to succeed in the host: Virulence and regulation. Clin. Microbiol. Rev. 26:308. doi: 10.1128/CMR.00066-12

Foley, S. L., Johnson, T. J., Ricke, S. C., Nayak, R., and Danzeisen, J. (2013). Salmonella Pathogenicity and Host Adaptation in Chicken-Associated Serovars. Microbiol. Mol. Biol. Rev. 77, 582-607. doi: 10.1128/mmbr.00015-13

Fry, B., Zhu, T., Domach, M. M., Koepsel, R. R., Phalakornkule, C., and Ataai, M. M. (2000). Characterization of growth and acid formation in a Bacillus subtilis pyruvate kinase mutant. Appl. Environ. Microbiol. 66, 4045-4049. doi: 10.1128/aem.66.9.4045-4049.2000

Gal-Mor, O., Boyle, E. C., and Grassl, G. A. (2014). Same species, different diseases: How and why typhoidal and non-typhoidal Salmonella enterica serovars differ. Front. Microbiol. 5:391-391. doi: 10.3389/fmicb.2014.00391

Gaudy, A. F., Abu-Niaaj, F., and Gaudy, E. T. (1963). Statistical study of the spot-plate technique for viable-cell counts. Appl. Microbiol. 11, 305-309. doi: 10.1128/aem.11.4.305-309.1963

Giaouris, E., Heir, E., Desvaux, M., Hébraud, M., Møretrø, T., Langsrud, S., et al. (2015). Intra- and inter-species interactions within biofilms of important foodborne bacterial pathogens. Front. Microbiol. 6:841. doi: 10.3389/fmicb. 2015.00841

Hayashi, R. M., Lourenço, M. C., Kraieski, A. L., Araujo, R. B., Gonzalez-Esquerra, R., Leonardecz, E., et al. (2018). Effect of feeding Bacillus subtilis spores to broilers challenged with Salmonella enterica serovar Heidelberg Brazilian strain UFPR1 on performance, immune response, and gut health. Front. Vet. Sci. 5:13. doi: 10.3389/fvets.2018.00013

Huang, T., Geng, H., Miyyapuram, V. R., Sit, C. S., Vederas, J. C., and Nakano, M. M. (2009). Isolation of a variant of subtilosin A with hemolytic activity. J. Bacteriol. 2009, 541-549. doi: 10.1128/JB.00541-09

Hung, Y. T., Lay, C. J., Wang, C. L., and Koo, M. (2017). Characteristics of nontyphoidal Salmonella gastroenteritis in Taiwanese children: A 9-year period retrospective medical record review. J. Infect. Public Health. 10, 518-521. doi: 10.1016/j.jiph.2016.09.018

Jajere, S. M. (2019). A review of Salmonella enterica with particular focus on the pathogenicity and virulence factors, host specificity and adaptation and antimicrobial resistance including multidrug resistance. Vet. World 12 , 504-521. doi: 10.14202/vetworld.2019.504-521

Jesudhasan, P. R., Cepeda, M. L., Widmer, K., Dowd, S. E., Soni, K. A., Hume, M. E., et al. (2010). Transcriptome analysis of genes controlled by luxS/Autoinducer-2 in Salmonella enterica serovar Typhimurium. Foodborne Pathog. Dis. 7, 399410. doi: 10.1089/fpd.2009.0372
Karlyshev, A. V., Melnikov, V. G., and Chikindas, M. L. (2014a). Draft genome sequence of Bacillus subtilis strain KATMIRA1933. Genom. Ann. 2, e619-e614. doi: 10.1128/genomeA.00619-14

Karlyshev, A. V., Melnikov, V. G., and Chistyakov, V. A. (2014b). Draft genome sequence of Bacillus amyloliquefaciens B-1895. Genom. Ann. 2, e633-e614. doi: 10.1128/genomeA.00633-14

Kurtz, J. R., Goggins, J. A., and McLachlan, J. B. (2017). Salmonella infection: Interplay between the bacteria and host immune system. Immunol. Lett. 190, 42-50. doi: 10.1016/j.imlet.2017.07.006

Lamas, A., Regal, P., Vázquez, B., Miranda, J. M., Cepeda, A., and Franco, C. M. (2018). Salmonella and Campylobacter biofilm formation: a comparative assessment from farm to fork. J. Sci. Food Agri. 98, 4014-4032. doi: 10.1002/jsfa. 8945

Longhi, C., Scoarughi, G. L., Poggiali, F., Cellini, A., Carpentieri, A., Seganti, L., et al. (2008). Protease treatment affects both invasion ability and biofilm formation in Listeria monocytogenes. Microb. Pathog. 45, 45-52. doi: 10.1016/ j.micpath.2008.01.007

Makarenko, M. S., Chistyakov, V. A., Usatov, A. V., Mazanko, M. S., Prazdnova, E. V., Bren, A. B., et al. (2019). The Impact of Bacillus subtilis KATMIRA1933 Supplementation on Telomere Length and Mitochondrial DNA Damage of Laying Hens. Probiotics Antimicrob. Proteins. 11, 588-593. doi: 10.1007/s12602018-9440-9

Mauriello, G., De Luca, E., La Storia, A., Villani, F., and Ercolini, D. (2005). Antimicrobial activity of a nisin-activated plastic film for food packaging. Lett. Appl. Microbiol. 41, 464-469. doi: 10.1111/j.1472-765X.2005.01796.x

Mazanko, M. S., Gorlov, I. F., Prazdnova, E. V., Makarenko, M. S., Usatov, A. V., Bren, A. B., et al. (2018). Bacillus Probiotic Supplementations Improve Laying Performance, Egg Quality, Hatching of Laying Hens, and Sperm Quality of Roosters. Probiotics Antimicrob. Proteins 2018, 9369-9364. doi: 10.1007/ s12602-017-9369-4

Mazanko, M. S., Makarenko, M. S., Chistyakov, V. A., Usatov, A. V., Prazdnova, E. V., Bren, A. B., et al. (2019). Probiotic Intake Increases the Expression of Vitellogenin Genes in Laying Hens. Probiotics Antimicrob. Proteins. 10, 367-373. doi: 10.1007/s12602-019-9519-y

McDonagh, A., Leibler, J. H., Mukherjee, J., Thachil, A., Goodman, L. B., Riekofski, C., et al. (2019). Frequent human-poultry interactions and low prevalence of Salmonella in backyard chicken flocks in Massachusetts. Zoon. Public Health. 66, 92-100. doi: 10.1111/zph.12538

Melian, C., Segli, F., Gonzalez, R., Vignolo, G., and Castellano, P. (2019). Lactocin AL705 as quorum sensing inhibitor to control Listeria monocytogenes biofilm formation. J. Appl. Microbiol. 127, 911-920. doi: 10.1111/jam.14348

Monteagudo-Mera, A., Rastall, R. A., Gibson, G. R., Charalampopoulos, D., and Chatzifragkou, A. (2019). Adhesion mechanisms mediated by probiotics and prebiotics and their potential impact on human health. Appl. Microbiol. Biotechnol. 103, 6463-6472. doi: 10.1007/s00253-019-09978-7

Montville, T., and Matthews, K. (2008). Food Microbiology: An Introduction, 2nd Edn. Washington, USA: ASM Press.

Mulani, M. S., Kamble, E. E., Kumkar, S. N., Tawre, M. S., and Pardesi, K. R. (2019). Emerging strategies to combat ESKAPE pathogens in the era of antimicrobial resistance: A review. Front. Microbiol. 10:539. doi: 10.3389/fmicb.2019. 00539

Nair, D. V. T., Venkitanarayanan, K., and Johny, A. K. (2018). Antibiotic-resistant Salmonella in the food supply and the potential role of antibiotic alternatives for control. Foods. 7:167. doi: 10.3390/foods7100167

Nikiforova, O. A., Klykov, S., Volski, A., Dicks, L. M. T., and Chikindas, M. L. (2016). Subtilosin A production by Bacillus subtilis KATMIRA1933 and colony morphology are influenced by the growth medium. Ann. Microbiol. 66, 661671. doi: 10.1007/s13213-015-1149-3

O’Bryan, C. A., Crandall, P. G., and Ricke, S. C. (2018). “'Antimicrobial Resistance in Foodborne Pathogens," in Food and Feed Safety Systems and Analysis, eds S. C. Ricke, G. G. Atungulu, C. E. Rainwater, and S. H. Park (Cambridge, MA: Academic Press), 99-115. doi: 10.1016/B978-0-12-811835-1.00006-3

Ohara, H. and Yahata, M. (1996). L-Lactic acid production by Bacillus sp. in anaerobic and aerobic culture. J. Ferment. Bioeng. 81, 272-274. doi: 10.1016/ 0922-338X(96)82222-7

Popova, T. (2017). Effect of probiotics in poultry for improving meat quality. Curr. Opin. Food Sci. 14, 72-77. doi: 10.1016/j.cofs.2017.01.008 
Prazdnova, E. V., Mazanko, M. S., Chistyakov, V. A., Denisenko, Y. V., Makarenko, M. S., Usatov, A. V., et al. (2019). Effect of Bacillus subtilis KATMIRA1933 and Bacillus amyloliquefaciens B-1895 on the productivity, reproductive aging, and physiological characteristics of hens and roosters. Benef. Microbes 10, 395-412. doi: 10.3920/BM2018.0149

Shelburne, C. E., An, F. Y., Dholpe, V., Ramamoorthy, A., Lopatin, D. E., and Lantz, M. S. (2007). The spectrum of antimicrobial activity of the bacteriocin subtilosin A. J. Antimicrob. Chemother. 59, 297-300. doi: 10.1093/jac/dkl495

Sutyak, K. E., Anderson, R. A., Dover, S. E., Feathergill, K. A., Aroutcheva, A. A., Faro, S., et al. (2008). Spermicidal activity of the safe natural antimicrobial peptide subtilosin. Infect. Dis. Obstet. Gynecol. 2008, 540758. doi: 10.1155/2008/ 540758

Vijayababu, P., Samykannu, G., Antonyraj, C. B., Thomas, J., Narayanan, S. B., Basheer Ahamed, S. I., et al. (2018). Patulin interference with ATP binding cassette transferring auto inducer -2 in Salmonella typhi and biofilm inhibition via quorum sensing. Inform. Med. Unlocked. 11, 9-14. doi: 10.1016/j.imu.2018. 02.001

Vuotto, C., Longo, F., and Donelli, G. (2014). Probiotics to counteract biofilmassociated infections: Promising and conflicting data. Int. J. Oral Sci. 6, 189-194. doi: 10.1038/ijos.2014.52

Wang, X., Zhu, S., Zhao, J. H., Bao, H. X., Liu, H., Ding, T. M., et al. (2019a). Genetic boundaries delineate the potential xhuman pathogen Salmonella bongori into discrete lineages: Divergence and speciation. BMC Genom. 20:930. doi: 10.1186/ s12864-019-6259-z

Wang, Y., Yan, X., Han, D., Liu, Y., Song, W., Tong, T., et al. (2019b). Lactobacillus casei DBN023 protects against jejunal mucosal injury in chicks infected with
Salmonella pullorum CMCC-533. Res. Vet. Sci. 2019, 09.010. doi: 10.1016/j.rvsc. 2019.09.010

Wiedemann, A., Virlogeux-Payant, I., Chaussé, A.-M., and Velge, P. (2014). Interactions of Salmonella with animals and plants. Front. Microbiol. 5:791. doi: 10.3389/fmicb.2014.00791

Xu, L., Li, H., Vuong, C., Vadyvaloo, V., Wang, J., Yao, Y., et al. (2006). Role of the luxS quorum-sensing system in biofilm formation and virulence of Staphylococcus epidermidis. Infect. Immun. 74, 488-496. doi: 10.1128/IAI.74.1. 488-496.2006

Zhang, B., Ku, X., Zhang, X., Zhang, Y., Chen, G., Chen, F., et al. (2019). The AI-2/luxS quorum sensing system affects the growth characteristics, biofilm formation, and virulence of Haemophilus parasuis. Front. Cell. Infect. Microbiol. 9:62. doi: 10.3389/fcimb.2019. 00062

Conflict of Interest: The authors declare that the research was conducted in the absence of any commercial or financial relationships that could be construed as a potential conflict of interest.

Copyright (C) 2021 Tazehabadi, Algburi, Popov, Ermakov, Chistyakov, Prazdnova, Weeks and Chikindas. This is an open-access article distributed under the terms of the Creative Commons Attribution License (CC BY). The use, distribution or reproduction in other forums is permitted, provided the original author(s) and the copyright owner(s) are credited and that the original publication in this journal is cited, in accordance with accepted academic practice. No use, distribution or reproduction is permitted which does not comply with these terms. 